\section{告}

МРНТИ 14.35.01

УДК 378

DOI 10.47940/cajas.v5I4.293

\section{ОЛЕГ КУСКАШЁВ ${ }^{1}$}

${ }^{1}$ Федеральное государственное казённое военное образовательное учреждение высшего образования «Военный университет» (г. Москва, Россия)

\section{ВЗАИМОПРОНИК-}

НОВЕНИЕ МУЗЫКИ

В ОРКЕСТРОВОМ

ИСПОЛНЕНИИ

В СУЩНОСТЬ

КИНЕМАТОГРАФИИ

XX И XXI ВЕКОВ

\title{
ВЗАИМОПРОНИКНОВЕНИЕ МУЗЫКИ В ОРКЕСТРОВОМ ИСПОЛНЕНИИ В СУЩНОСТЬ КИНЕМАТОГРАФИИ ХХ И ХХІ ВЕКОВ
}

\section{Аннотация}

В статье использованы исторические источники, отражающие достоверность обобщенных и анализированных фактов разных эпох, во взаимосвязи и взаимопроникновении синтеза искусств, которые способствуют формированию мировоззрения. Использованные определенные закономерности и специфика взаимопроникновения музыки в оркестровом исполнении в сущность и замысел фильма характеризуют и подчеркивают развитие кинематографа как мощного социокультурного феномена. Подтверждением служит тот факт, что именно благодаря великой силе музыки в оркестровом исполнении, написанной композиторами, и таланту музыкантов, исполняющих гениальные музыкальные творения, во взаимопроникновении в замысел фильмов, созданных режиссерами, делают уникальной кинематографию.

Необходимо отметить, что массовые направления, возникшие в XX веке, продолжают формировать современную систему искусства, сосуществуя и активно взаимодействуя в рамках культуры, признаны многими культурологами, музыковедами, композиторами. Не исключен тот факт, что до настоящего времени наследие продолжает осваиваться, разрабатываться, осмысляться в кинематографии XX и XXI веков и далеко еще не изжило себя, поэтому продолжает быть актуальным и проблемным, вызывая широкий интерес у исследователей. Выбранная нами тема с учетом всех высказываний, мыслей и анализа научных работ определенного направления не случайна, она подчеркивает проблемность, неисчерпанность по сегодняшний день, будоражит мысли многих начинающих исследователей, ставших на этот путь в поиске ответа и получения результатов на поставленные вопросы. Данная тема направляет начинающего исследователя к более глубокому осмыслению и изучению взаимосвязи 
теории и истории кино, музыки, оркестрового исполнительства для поиска новых отправных точек и изломов процесса культурно-исторического развития кинематографии.

Ключевые слова: проблема, взаимопроникновение, исторические источники, специфика, закономерность, сущность, кинематография, оркестровое исполнение, замысел, музыка, творческий поиск.

\section{Введение}

Из исторических источников, собранных в течение многих лет исследователями, известно, что проблема взаимопроникновения и взаимообогащения культур не сводится лишь к описанию и анализу разнообразных этнокультурных процессов. Не случайно перед учеными всего мира стоит теоретический вопрос: все ли сферы той или иной культурной общности одинаково проницаемы [1-3]. Учитывая достоверность многих фактов для раскрытия содержания статьи, мы опирались на исторические источники, обобщая и анализируя теоретические и практические стороны выбранной темы [4-6]. Фактически нами выявлено, что во все эпохи разные виды искусств оказывают друг на друга влияние и, несмотря на специфику каждого из них, находятся в некоторой взаимосвязи. Взаимопроникая, они образуют определенную систему для сотрудничества; объединяясь, образуют синтез, причем эти взаимоотношения и синтезы различны.

Важнейшая проблема заключается в том, что во все времена человечество всегда находится в постоянном творческом и теоретическом поиске: какое место должна занимать музыка в кинематографии в оркестровом исполнении [7]. Принято считать, что эволюция различных смешанных видов искусств привела к тому, что музыка в оркестровом исполнении глубоко проникла в кинематографию, начала дополнять саму зрительную составляющую, при этом увеличивая либо противопоставляя всю выразительность зрительного элемента. Если допустить, что зрительный кадр конкретизирует, то оркестровая музыка даёт обобщенную характеристику и тем самым усиливает воздействие изображения. Вот в чём, по существу, состоит взаимодействие обоих компонентов, при этом не исключая само взаимодействие, подготовленное условностями, выработанными на почве синтетических жанров в современности.

\section{Методы}

Развитие кинематографа как мощного социокультурного феномена сразу повлияло на наполненность и выстроенность художественного пространства, которое, оставаясь в постоянстве, становилось мощным генератором формирования мировоззрения. С годами усиленное социально-пространственными законами, обусловленными тем, что в ходе взаимодействия, разворачивающегося в определенной материальной среде и в определенный момент социального и физического времени, обогащаясь, продвигает вперед возникновение нового системного качества, признаки, которого, проявляясь, иногда отсутствуют в элементах ситуации. В процессе длительного наблюдения можно отметить, что, попав в одно поле, люди, разные по своему характеру, взглядам и манерам поведения, начинают вести себя сходным образом. 
Тогда как музыка шла рука об руку с кино с самого его рождения, на что конкретно обращают внимание с первого сеанса братьев Люмьер в 1895 году. Более 170 лет назад великий классик Эдвард Григ заметил, что "слова иногда нуждаются в музыке, но музыка никогда не нуждается ни в чем". Благодаря этому лучшие фильмы содержат в себе истинные музыкальные шедевры [8].

Работа в кино предъявляет к музыкальному оркестру особые требования. Запись музыки в оркестровом исполнении к фильму проходит в условиях строгих временных рамок почти без репетиций. Этот труд требует высокого профессионального мастерства каждого исполнителя-музыканта оркестра, четкости и собранности, музыкальной чуткости и быстрого понимания замысла композитора [9]. Всеми этими качествами в полной мере обладает Российский государственный симфонический оркестр кинематографии, для которого практически не существует невыполнимых задач. На сегодняшний день он является одним из самых мобильных оркестров, способных играть в любых больших и малых составах, трансформироваться в эстрадный и джазовый ансамбль, выступать в филармонических концертах.

Учитывая данные из источников, необходимо отметить, что выбранная тема особенно актуальна в наши дни, в эпоху развития кино и телевидения. Музыка в оркестровом исполнении разновидность искусства, воплощающая идейно-эмоциональное содержание в звуковых художественных образах, она способна создать настроение, необходимое для просмотра того или иного фильма. Кто-то считает её неотьемлемой частью кино, некоторые же, напротив, только "хорошей приправой" [10]. Так или иначе, без оркестрового музыкального сопровождения, написанного композитором, трудно себе представить любой фильм, созданный режиссером, сценаристом, артистами, что еще раз доказывает взаимопроникновение и обогащение творческого союза.

На наш взгляд, нельзя отрицать тот факт, что материалы, скрупулезно собранные нами из исторических источников, в том числе и зарубежных, еще раз доказывают, что музыка в оркестровом исполнении по сегодняшний день играет одну из важнейших ролей в кинематографе. В статье мы подчеркиваем цель голливудских композиторов и системность их творчества, неизменно сочетающуюся с некоторым стремлением к обновлению [11]. Необходимо отметить, что в то же время предпочтение, отдаваемое "испытанным" музыкальным приемам, объясняется не приверженностью традициям, а главенством в коммерческом искусстве коммуникативного элемента: киномузыка в Голливуде служит не “абсолютным ценностям", а потребностям современных людей в сильных и разнообразных впечатлениях, в расширении своего повседневного жизненного пространства с помощью "фабрики грез" [12].

Поскольку многие историки зарубежья позволяли соотносить хронометраж сцены с протяженностью музыкального фрагмента, а также рассматривали именно эмоциональносмысловое соответствие музыкального "цитатного" материала с сюжетнособытийным содержанием киносцен, установление эмоциональнообразного контакта с изображением и режиссёрским замыслом [12]. 
Поэтому можно отметить, что на ранней стадии становления кинематографа многими режиссёрами была осознана потребность в привлечении к работе над фильмом профессиональных композиторов.

Однако необходимо отметить, что вместе с тем сугубо музыковедческий подход к исследованию музыки кино далеко не всегда позволял достичь позитивных и объективно взвешенных результатов, поскольку специфика музыки кино заключалась в её сосуществовании с речью и шумами в едином игровом пространстве, в трактовке и подчинении режиссёрскому замыслу кинематографии. Все эти технические моменты и замыслы режиссера способствовали предъявлению особых требований к технике композиторского письма, отличной от техники при написании автономных музыкальных сочинений [13].

Невозможно не согласиться с высказыванием Ижиковского, который сорок лет назад констатировал, что именно «кино расширяет видимый мир человека...", считая, что во главе ставится замысел режиссера. Тогда как образ музыки лишь подчеркивает в целом восприятии кинокартины свой "Второй план" [10].

Однако необходимо признать, что именно в совокупности они способствуют продвижению и зрительной сферы фильма, и музыкального оформления в активизации замысла и глубокого содержания фильма, тогда как, по мнению М. Мартена, из общих функций признается за музыкой лишь создание эмоциональной атмосферы фильма [14].

Возвращаясь к истокам, примерно до середины 30-х годов прошлого века, хотелось бы отметить, что в теоретических работах и на практике применялись на правах тождественности два понятия: "музыка в кино" и "музыка в фильме". Позднее была предпринята попытка заменить их одним универсальным термином "киномузыка", акцентировавшим её прикладную принадлежность, видимо, по аналогии с оперной, театральной, цирковой музыкой.

Хотелось бы подчеркнуть, что именно в начале 70-х годов киновед Ирина Шилова подвергла критике понятие "киномузыка", сочтя его довольно-таки неопределённым, в результате чего в сферу действия киномузыки попадала, по мнению автора, многочисленная низкопробная и ремесленная продукция, ориентированная на воспроизведение стандартных формклише массово-развлекательной и нейтрально-фоновой музыки. Исходя из этого, И. Шилова предложила заменить понятие "киномузыка" другим - "музыка фильма" [3].

\section{Результаты}

Учитывая многолетний опыт, противоречивые высказывания историков искусства, накопленные за всю историю звукового кино, отмечаем, что многие молодые аспиранты, которые встают на путь исследования, не только трактуют свое мнение, но и предлагают гораздо более широкое и разностороннее рассмотрение взаимопроникновения музыки в оркестровом исполнении в развитие художественного образа фильма. Это обусловлено тем, что музыка в кинематографе при взаимодействии то с кадром, то со словом, то с монтажным строем, то со всем вместе приобретает новые функции и вместе с тем новые качества, во многом отличающие ее от музыки как самостоятельного искусства [13]. 


\section{Обсуждение}

Невозможно не заметить более прогрессивные и далеко идущие замыслы режиссеров и композиторов, которые, создавая свои шедевры в кинематографии, не забывают закреплять исторические факты, считая, что в кинематографии допустимо использование новаторских звуковых средств именно в силу их специфического функционирования. Оттого что музыка в оркестровом исполнении во многих фильмах комментирует кинокадр и одновременно комментируется кинокадром, слушатель может постичь ее "смысл", даже если в ней используются современные непривычные средства, что подчеркивает свободный выбор у композитора и режиссера в целом для взаимопроникновения музыки в сущность фильма [15].

\section{Заключение}

Среди весьма многочисленного списка научных работ исследователей, выборочно использованных исторических источников в статьях, посвящённых данной проблематике, следует выделить определенную закономерность, которая усиливает атмосферу фильма, увеличивает возможность погружения в его сущность, в наш разум. Подтверждающий факт: благодаря великой силе музыки в оркестровом исполнении, написанной композиторами, и таланту музыкантов, создающих гениальные музыкальные творения, во взаимопроникновении в замысел фильмов, созданных режиссерами, делают уникальной кинематографию.

Всем известно, что именно хорошая музыка может вызвать у зрителя эмоциональное состояние, нужное для восприятия происходящего на экране, задуманного режиссером при создании фильма. И только при профессионально грамотном подходе к содержанию и замыслу фильма любые переходные части могут выиграть от музыки, особенно если она создает более приподнятое настроение, поэтому взаимопроникновение и взаимообогащение усиливают восприятие целостного, задуманного для получения конечного результата. Отечественное киноискусство XX века это неотьемлемая часть культуры российского общества, развитие которой во многом зависело от политики и экономики, мировоззренческих ориентиров социума. Более того, специфика кинематографии и ее культурного продукта - фильма, в совокупности с музыкальным сопровождением, не только может демонстрировать готовность как к созиданию целесообразности в выполнении определенных задач, но и взаимопроникая для создания целого, обладает уникальной силой, которая действует на человечество как нечто направляющее, вдохновляющее, способное на контакт с нашей душой и внутренним миром. 


\section{Список источников:}

1. Трёльч Э. Историзм и его проблемы. Культурология. XX век: Антология. - М.: Юрист, 1995. 720 с.

2. Зоркая Н. М. История советского кино. - СПб., Алетейя, 2005. 544 с.

3. Фрейлих С.И. Теория кино: От Эйзенштейна до Тарковского. - М., 2002. 512 с. Шимонова, Н. В. Музыка в кинематографе. Опыт анализа музыкальной партитуры фильма на примере трех экранизаций произведений М. Булгакова / Н. В. Шимонова. - Текст: непосредственный // Молодой ученый. - 2015. - № 18 (98). С. 434-439.

4. Полегаева Е. Р. Развитие экранного языка и его взаимодействие с классическими искусствами. Автореф. дис. на соиск. учен. степ. канд. искусствоведения: (17.00.03). - М., Искусство, 1982.

5. Шилова И. М. Фильм и его музыка. - М., Советский композитор, 1973. $230 \mathrm{c.}$

6. Лисса 3. Эстетика киномузыки. - М., Искусство, 1970. 430 с.

7. Лондон К. Музыка фильма. - М., Госкиноиздат, 1937. 314 с.

8. Балаш Б. Кино: Становление и сущность нового искусства / пер. с нем. М. П. Брандес. - М., Прогресс, 1968. - 328 с.

9. Aleksandr Prokhorov. Cinema of Attractions versus Narrative Cinema: Leonid Gaidai's Comedies and Eldar Ryazanov's Satires of the 1960s // Slavic Review. 2003. - Vol.62 (3). P. 455-472.

10. Swift Anthony E. Popular Theatre and Society in Tsarist Russia. University of California Press, 2002. - 346 p.

11. Рычков К. Н. Музыка в современном коммерческом кинематографе США: проблемы истории и теории: Автореф. дис. ... канд. искусствоведения. - М., 2013. 30 с. [Электрон.ресурc]. - URL: http://cheloveknauka.com/muzyka-vsovremennom-kommercheskom-kinematografe-ssha\#ixzz6PnREcA9q - [Дата обращения: 19.02.2020].

12. Дворниченко О. И. Музыка как элемент экранного синтеза. - М., Искусство, 1975. -266 c.

13. Ковтонюк Ф. В. Социально-экономические особенности и этапы исторического развития киноиндустрии на примере США и России // Экономический журнал. - 2016. - №5 (41). С.126-150

14. Мусский И. А. 100 великих отечественных кинофильмов. - М., Вече, 2005. $-480 \mathrm{c}$.

\section{References:}

1. Trol'ch E. Istorizm i yego problemy [Historicism and its problems]. Culturology. XX century: Anthology. - M .: Jurist, 1995.720 p. (in Russian)

2. Zorkaya N. M. Istoriya sovetskogo kino [History of Soviet cinema]. - SPb., Aleteyya, 2005. - 544 p. (in Russian)

3. Freylikh S. I. Teoriya kino: Ot Eyzenshteyna do Tarkovskogo [Film theory: From Eisenstein to Tarkovsky]. - M., 2002. - 512 p. (in Russian)

4. Shimonova, N. V. Muzyka v kinematografe. Opyt analiza muzykal'noy partitury fil'ma na primere trekh ekranizatsiy proizvedeniy M. Bulgakova [Music in cinematography. The experience of analyzing the musical score of a film on the example of three screen adaptations of M. Bulgakov's works]. N. V. Shimonova. 
- Text: neposredstvennyy // Molodoy uchenyy. - 2015. - № 18 (98). P. 434-439. (in Russian)

5. Polegayeva Ye. R. Razvitiye ekrannogo yazyka i yego vzaimodeystviye s klassicheskimi iskusstvami [Development of the screen language and its interaction with the classical arts]. - M., Iskusstvo, 1982. (in Russian)

6. Shilova I. M. Fil'm i ego muzyka [The film and its music]. - M .: Soviet composer, 1973. - 230 p. (in Russian)

7. Lissa Z. Estetika kinomuzyki [The aesthetics of film music]. - M., Art, 1970. - 430 p. (in Russian)

8. London K. Muzyka fil'ma [Film music]. - M., Goskinoizdat, 1937. - 314 p. (in Russian)

9. Balash B. Kino: Stanovlenie i sushchnost' novogo iskusstva [Cinema: The Formation and Essence of New Art] / per. with him. M. P. Brandes. M., Progress, 1968. - 328 p. (in Russian)

10. Aleksandr Prokhorov. Cinema of Attractions versus Narrative Cinema: Leonid Gaidai's Comedies and Eldar Ryazanov's Satires of the 1960s // Slavic Review. 2003. - Vol.62 (3). - P. 455-472.

11. Swift Anthony E. Popular Theatre and Society in Tsarist Russia. University of California Press, 2002. - 346 p.

12. Rychkov K. N. Muzyka v sovremennom kommercheskom kinematografe SSHA: problemy istorii i teorii:[Music in modern commercial cinema in the United States: problems of history and theory:] Avtoref. dis. ... kand. iskusstvovedeniya. - M., 2013. 30 p. [http://cheloveknauka.com/muzykav-sovremennom-kommercheskom-kinematografe-ssha\#ixzz6PnREcA9q accessed on 19.02.2020].

13. Dvornichenko O. I. Muzyka kak element ekrannogo sinteza [Music as an element of on-screen synthesis]. - M., Art, 1975. 266 p. (in Russian)

14. Kovtonyuk F. V. Sotsial'no-ekonomicheskiye osobennosti i etapy istoricheskogo razvitiya kinoindustrii na primere SSHA i Rossii [Socioeconomic characteristics and stages of the historical development of the film industry on the example of the USA and Russia] // Ekonomicheskiy zhurnal. - 2016. - №5 (41). - P.126-150. (in Russian)

15. Musskiy I. A. 100 velikikh otechestvennykh kinofil'mov [100 great Russian films]. - M., Veche, 2005. - 480 p. (in Russian)

\section{Олег Кускашёв}

«Әскери Университет» Федералды мемлекеттік қазынашылық жоғары оқу орны (Мәскеу, Ресей)

\section{XX-XXI ҒАСЫРЛЫҚ КИНЕМАТОГРАФИЯ МӘНІНДЕГІ ОРКЕСТРЛІК ОРЫНДАУҒА МУЗЫКАНЫН ӨЗАРА ЕНУІ}

\section{Аңдатпа}

Мақалада дүниетанымның қалыптасуына ықпал ететін өнер синтезінің өзара байланысы мен интерпенетрациясында әртүрлі дәуірлердегі жалпыланған және талданған фактілердің сенімділігін көрсететін тарихи дерек көздері қолданылады. Фильмнің мәні мен тұжырымдамасына оркестрлік 
орындаудағы музыканың енуінің белгілі бір заңдылықтары мен ерекшелігі киноның қуатты әлеуметтікмәдени құбылыс ретінде дамуын сипаттайды және баса көрсетеді. Кинематографияны қайталанбас етіп жасайтын режиссерлер жасаған фильм идеясына өзара ену кезінде тамаша музыкалық туындылар жасаушы композиторлар мен музыканттардың талантымен ойластырылған оркестрлік орындаудағы музыканың зор күшінің арқасында екендігі бұны дәлелдейді.

XX ғасырда пайда болған бұқаралық тенденциялар көптеген мәдениеттанушылар, музыкатанушылар, композиторлар мойындаған мәдениеттің шеңберінде қатар өмір сүріп, белсенді өзара әрекеттесіп, заманауи өнер жүйесін қалыптастыра беретіндігін атап өткен жөн. Мұраның XX және XXI ғасырлардағы кинематографияда сіңірілуі, дамуы және түсінілуі жалғасатыны және оның пайдалылығынан әлі де асып түспегендігі, сондықтан ол зерттеушілердің кең қызығушылығын тудырған өзекті мәселе болып қала беретіні де жоқ емес. Ғылыми еңбектердегі зерттеушілердің белгілі бір бағыттарының барлық тұжырымдары, ойлары мен талдауларын ескере отырып, олар проблемалық табиғатты баса назар аударатын тақырыпты кездейсоқ таңдауымызға ықпал етті, осы күнге дейін сарқылмады, жауап іздеу және жинақ үшін нәтиже алу жолында осы жолға түскен көптеген бастаушы зерттеушілердің ойларын қозғады. Таңдалған тақырып жаңадан бастаған зерттеушінің ойларын кинематографияның мәденитарихи дамуы үдерісіндегі жаңа бастапқы нүктелер мен үзілістерді іздеу мақсатында кино, музыка, оркестр орындау теориясы мен байланысын тереңірек түсінуге және зерттеуге бағыттайды.

тірек сөздер: мәселе, өзараенушілік, тарихи дерек көздері, ерекшелігі, заңдылығы, мәні, кинематография, оркестрлік орындау, тұжырымдама, музыка, шығармашылық ізденіс.

\section{Oleg Kuskashev}

Federal State Treasury Military Educational Institution of Higher Education "Military University" (Moscow, Russia)

\section{MUTUAL RELATIONSHIP IN ORCHESTRA PERFORMANCE IN THE ESSENCE OF CINEMATOGRAPHY OF THE XX AND XXI CENTURIES}

\section{Abstract}

The article uses historical sources that reflect the reliability of the generalized and analyzed facts of different eras, in the interconnection and interpenetration of the synthesis of arts, which contribute to the formation of a worldview. The used certain laws and specifics of the interpenetration of music in orchestral performance into the essence and purpose of the film characterize and emphasize the development of cinema as a powerful sociocultural phenomenon. Confirmation is the fact that it is thanks to the great power of music in orchestral performance, conceived by composers and the talent of musicians who create ingenious musical creations in the interpenetration of the idea of the film, created by the directors, make cinematography unique.

It should be noted that the mass trends that emerged in the twentieth century continue to form the modern system of art, coexisting and actively interacting within the framework of culture, recognized by many culturologists, musicologists, composers. It is not excluded that the heritage continues to be assimilated, developed, and comprehended in the cinematography of the 20th and 21st centuries and has not yet outlived its usefulness, therefore it continues to be relevant and problematic, arousing wide interest among researchers. Taking into account all the statements, thoughts and analysis of a certain direction of researchers in scientific works, they contributed not to our random choice of a topic that will emphasize the problematic nature, not exhausted to this day, agitating the thoughts of many novice researchers who have 
taken this path in search of an answer and obtaining results for the set questions. The chosen topic directs the thoughts of a novice researcher to a deeper understanding and study of the relationship between the theory and history of cinema, music, orchestral performance in order to search for new starting points and breaks in the process of cultural and historical development of cinematography.

Key words: problem, interpenetration, historical sources, specificity, regularity, essence, cinematography, orchestral performance, design, music, creative search.

\section{Автор туралы мәлімет:}

Қускашёв Олег Игоревич - Әскери Университет Адъюнкті, ӘУ - Әскери университеттің Әскери институты 41 - бөлім (әскери дирижер) ӘИ (ӘД) (Мәскеу, Ресей)

ORCID ID: 0000-0002-0327-1581

email: olimp-oi@yandex.ru

\section{Сведения об авторе:}

Кускашёв Олег Игоревич - адъюнкт Военного университета 41 -я кафедра (военно-дирижерская) ВИ (ВД) ВУ - военного института (военных дирижеров) Военного университета (Москва, Россия)

ORCID ID: 0000-0002-0327-1581

email: olimp-oi@yandex.ru

\section{Author's bio:}

Kuskashev Oleg Igorevich - Adjunct of the Military University

41st department (military conductor) VI (VD) VU - military institute (military conductors) of the Military University

(Moscow, Russia)

ORCID ID: 0000-0002-0327-1581

email: olimp-oi@yandex.ru 